\section{Fossil Lungfish from Australia}

\section{from a Correspondent}

LUNGFISHES (Dipnoi), because of their close similarity in form to certain living amphibians, have always enjoyed a special place in the study of vertebrate evolution. The most primitive surviving lungfish, Neoceratodus forsteri, is found in Australia, and there is a certain piquancy in that one of the oldest known lungfishes, Dipnorhynchus sussmilchi, comes from the marine, early Devonian of the same continent. The structure and relationships of this Devonian lungfish are the subjects of a recent article by $\mathrm{K}$. S. Thomson and K. S. W. Campbell (Bull. Peabody Mus. Nat. Hist., 38; 1971).

The skull roof of this primitive dipnoan seems essentially to have consisted of a mosaic of bones, and this is believed by some authors (for example, Westoll) to approach the condition in primitive bony fish. Thomson and Campbell re-evaluate the dermal bone patterns in Dipnoi, having assumed that Dipnorynchus shows the most primitive pattern of dermal roofing bones. Why they make this assumption is not made clear, but it is presumably because of the age of the specimens. This is perhaps a dangerous presumption when the sparse and spotty fossil record of lungfishes is considered and it does not accord easily with some of the discussion in the last part of the article.

Using their model of the primitive condition (Dipnorhynchus), Thomson and Campbell discuss the pattern in other lungfishes in which there are fewer bones, assuming loss ("space capture")

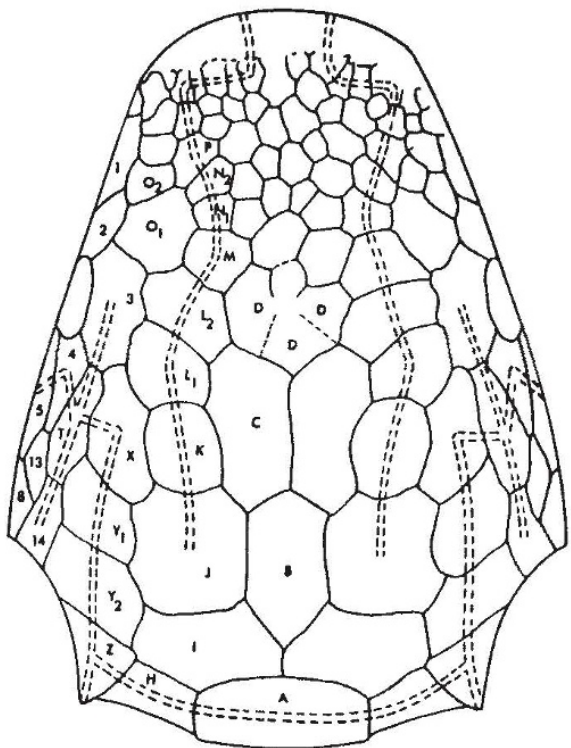

Thomson and Campbell's restoration of the skull roof of Dipnorphynchus sussmilchi (from Bull. Peabody Mus. Nat. Hist., 38; 1971). evolution. and/or fusion. One may well question, however, whether they have succeeded in their professed aim that "an integral sequential system of analysis should replace the current ad hoc approach to the identification of bones. That is, using a given bone, as a primary reference point, other bones should be defined in sequence; each definition must be cast only in terms of entities defined earlier in the sequence" (see, for example, their Fig. 2). Thomson and Campbell make no homologies with the roofing bone patterns seen in crossopterygians or actinopterygians, but in an admirably clear account of the lower jaw they reject analysis based on a "primitive" mosaic of bones and draw direct topographic homologies with rhipidistians.

In respect of the brain case Dipnorhynchus and other fossil dipnoans can be closely compared with Neoceratodus. There are, however, some unexpected features in the otic region of Dipnorhynchus. According to Thomson and Campbell a sulcus on the outer face of the neurocranium in front of the supposed foramen for the vagus nerve is interpreted as the lateral occipital fissure and the vagus itself seems to have issued from the labyrinth. Alternatively, some workers might reinterpret the vagus as the glossopharyngeal (so that this nerve has its normal relationships) and the lateral occipital fissure as representing the existing back end of the specimen, the occiput having fallen away.

Thomson and Campbell return to the problem of the dermal roofing bone pattern in the discussion, because the relationships of dipnoans depend primarily on the interpretation of these bones. The case for a close relationship between the lungfishes and crossopterygians is argued and this is valuable, but few ichthyologists will regard this as the last word on the subject. In comparison with crossopterygians, Thomson and Campbell have to assume that the skull roof of Dipnorhynchus is derived from ancestors with - fewer bones; this is a stumbling block because the subsequent evolution of lungfishes is generally agreed to involve the loss of bones and the acquisition of patterns not unlike those of other groups of fishes. Thomson and Campbell's view of lungfish evolution involves the acceptance of an abrupt and unexplained change in the direction of

In Thomson and Camptell's final analysis the new evidence presented on the dermal bone pattern of Dipnorynchus could equally be taken to support the conclusion that the Dipnoi are no more closely related to crossopterygians than to actinopterygians, but most workers will agree with the authors that the closest relatives of lungfishes are to be found among bony fishes.

\section{PROTEIN SYNTHESIS \\ Eliminating Mistakes}

from our Molecular Genetlcs Correspondent

EACH of the stages of protein synthesis seems to take place with a remarkable degree of fidelity and even in vitro systems in which the various components of the synthetic apparatus are derived from different organisms can make recognizable proteins. Aminoacyl-tRNA synthetases place amino-acids on only the appropriate transfer RNAs and the action of the ribosome ensures that transfer RNAs make few mistakes in recognizing their codons on messengers. In spite of the precautions which seem to be built into the synthetic apparatus, however, it seems that Escherichia coli has a special system which is responsible for ensuring that any proteins bearing an excessive number of errors are destroyed.

Gross mistakes can result when a nonsense mutant causes a premature termination of protein synthesis so that a protein fragment much shorter than usual is released into the cell. Mutant proteins of this nature, such as the lactose repressor or the $\beta$-galactosidase protein coded by the $z$ gene of the lactose operon, have a much shorter halflife than their full-sized counterparts. Most proteins in $E$. coli are stable, but some system seems to exist which degrades at least these particular mutants (see Nature, 228, 1138; 1970). Goldberg has now shown (Proc. US Nat. Acad. Sci., 69, 422; 1972) that some such mechanism operates on many mutant proteins and that it can also detect and degrade more subtle mistakes than prematurely terminated proteins.

The general activity of the degradative system was revealed by growing $E$. coli cells in the presence of puromycin; this antibiotic bears a resemblance to aminoacyl-tRNA and so is able to enter the ribosome in place of it and to react with a nascent protein to set free polypeptidyl-puromycin. In this way it causes a general premature termination of protein synthesis. Goldberg finds that the proteins made in the presence of the drug are degraded to free amino-acids much faster than are normal proteins.

As well as recognizing differences in size, however, differences in amino-acid composition also seem to provide grounds for degradation. The ram (ribosomal ambiguity) mutant of the $E$. coli ribosome causes mistakes to be made in the recognition of codons on 